DOI: http://dx.doi.org/10.5007/1980-3532.2015n14p24

\title{
Hierarquia, legitimidade e autoridade no processo de institucionalização da sociologia como disciplina escolar (1997-2008)
}

\author{
Hierarchy, legitimacy and authority on the sociology \\ institutionalization process as school discipline (1997-2008)
}

Livia Bocalon Pires de Moraes

Mestra em Ciências Sociais - UNESP

libocalon@hotmail.com

\begin{abstract}
Resumo: Este artigo busca analisar a institucionalização recente do ensino de sociologia no Ensino Médio, entre 1997 e 2008, com base na teoria sociológica de Pierre Bourdieu, em especial suas noções de poder simbólico, campo, capital e habitus, enfocando as ações de Amaury Cesar Moraes, Ileizi Luciana Fiorelli Silva, Sueli Guadelupe de Lima Mendonça, Elisabeth da Fonseca Guimarães, Nelson Dacio Tomazi, Heloisa Helena Teixeira de Souza Martins, e Lejeune Mato Grosso de Carvalho, cientistas sociais pioneiros neste processo. Enfatiza o envolvimento de cada um deles e a rede de relações pessoais e institucionais que gradativamente se constituiu, bem como suas concepções e representações acerca de suas ações e das relações atinentes a elas, e compreende as ações estratégicas que eles empreenderam a partir análise das diferentes posições hierárquicas ocupadas nos espaços sociais envolvidos com esta institucionalização.
\end{abstract}

Palavras-chave: Ensino de Sociologia. Institucionalização. Pierre Bourdieu.

Abstract: This article intends to analyses the recent institutionalization of teaching sociology in High School, between 1997 and 2008, based on the sociological theory of Pierre Bourdieu, specially his notions of symbolic power, field, capital and habitus, focusing the actions of Amaury Cesar Moraes, Ileizi Luciana Fiorelli Silva, Sueli Guadelupe de Lima Mendonça, Elisabeth da Fonseca Guimarães, Nelson Dacio Tomazi, Heloisa Helena Teixeira de Souza Martins, e Lejeune Mato Grosso de Carvalho, pioneers social scientists in this process. Emphasizes the involvement of each one and the network of personal and institutional relations that gradually constituted, as well as their conceptions and representations about their actions and the relationships relating to them, and comprehends the strategical actions that they undertook based in the analysis of different hierarchical positions occupied on the social spaces involved with this institutionalization.

Key-words: Teaching sociology. Institutionalization. Pierre Bourdieu.

Originais recebidos em: 10/03/2016

Aceito para publicação em: 03/05/2016

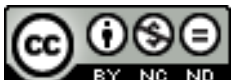

Comercial-Vedada a criação de obras derivadas 3.0 Unported License. 


\section{Introdução}

Este artigo é fruto do último capítulo de minha dissertação de mestrado, intitulada "Representando disputas, disputando representações: cientistas sociais e campo acadêmico no ensino de sociologia", que teve por intuito empreender uma reflexão sociológica, embasada na teoria de Pierre Bourdieu, sobre as ciências e os cientistas sociais, enfocando para tal o ensino de sociologia.

A partir da temática da institucionalização recente deste ensino no Ensino Médio, realizada entre os anos de 1997, em que o deputado federal Roque Zimmerman apresentou o Projeto de Lei $\mathrm{n}^{\circ} 3.178$, e 2008 , quando foi aprovada a Lei 11.684 , que instaurou a obrigatoriedade da sociologia como disciplina escolar, propus-me a refletir acerca dos conflitos, disputas, negociações, parcerias e mudanças decorrentes de tal empreendimento. Enfoquei as ações de alguns cientistas sociais diretamente responsáveis por sua concretização - Amaury Cesar Moraes, Ileizi Luciana Fiorelli Silva, Sueli Guadelupe de Lima Mendonça, Elisabeth da Fonseca Guimarães, Nelson Dacio Tomazi, Heloisa Helena Teixeira de Souza Martins, e Lejeune Mato Grosso de Carvalho - e busquei entender as relações que eles estabeleceram entre si e com outros indivíduos envolvidos nesse processo, como deputados, senadores, secretários da educação, membros do Conselho Nacional de Educação, e em especial com outros cientistas sociais.

Para isso, realizei com eles entrevistas semiestruturadas, em que abordei o envolvimento com o processo de institucionalização da obrigatoriedade do ensino de sociologia no Ensino Médio, a influência deste em suas trajetórias profissionais, a importância dos agentes e instituições envolvidos na condução deste movimento, as formas de organização adotadas, e as negociações e disputas em que foram protagonistas.

A partir delas, elaborei uma espécie de histórico desse processo, enfatizando o envolvimento de cada um deles e a rede de relações pessoais e institucionais que gradativamente se constituiu ao longo da movimentação empreendida para sua realização, bem como suas concepções e representações acerca de suas ações e das relações atinentes a elas, e analisei-as com base na teoria sociológica de Pierre Bourdieu, em especial nas noções de poder simbólico, campo, capital e habitus. 


\section{Histórico da institucionalização do ensino de sociologia}

O envolvimento no processo de organização com vistas à obrigatoriedade da disciplina escolar de sociologia, para cada um destes cientistas sociais, ocorreu de maneiras e por meio de instituições diversas. Todos eles de alguma forma, mantinham relações relativamente próximas com a questão do ensino, seja esta enquanto pauta sindical, objeto de estudos ou prática profissional.

Lejeune de Carvalho participou, em 1982, da fundação do Sindicato dos Sociólogos do estado de São Paulo (SINDSESP), em cuja diretoria atuou por cerca de 12 anos, tendo sido seu presidente e vice-presidente por mais de um mandato. Esteve também na presidência da Federação Nacional dos Sociólogos (FNSB) por mais de uma gestão, de modo que sua contribuição a este movimento se deu, sobretudo, enquanto líder sindical, sendo a obrigatoriedade do ensino de sociologia uma das lutas da categoria, embora, como ele destacou na entrevista, nem todos os sociólogos sejam professores de sociologia, pois segundo ele apenas o são os licenciados em ciências sociais. O envolvimento sindical com esta pauta não se daria, portanto, em busca da obtenção de vagas no mercado de trabalho.

Nós, por consciência política, até ideológica, vimos a importância deste
ensino, então faz parte das nossas plataformas de trabalho, das diretorias
eleitas desde o início do sindicato. Nós somos herdeiros de um movimento
nacional que vem de 1977, que é da Associação dos Sociólogos do Brasil.
Desde aquela época se falava, em plena ditadura, da sociologia no Ensino
Médio. Então eu sou fruto e herdeiro desse processo, e partícipe muito ativo.
- Lejeune de Carvalho

Nelson Tomazi é autor de livros didáticos de sociologia para o Ensino Médio, sendo o primeiro deles, Iniciação à Sociologia (Tomazi, 2000), escrito em conjunto com outros professores da Universidade de Londrina, e lançado em 1993. A partir da produção desse livro, o autor passou a estudar a temática do Ensino Médio, tendo sido convidado por Lejeune de Carvalho a compor uma mesa-redonda sobre sociologia no ensino médio, em um dos encontros de cursos realizados, no fim da década de 1990, pelo SINDSESP e pela FNSB. Passou a fazer parte, depois disso, da Federação Nacional dos Sociólogos, em uma espécie de departamento voltado ao ensino médio.

Elisabeth Guimarães, entre os anos de 1982 e 1984, ministrou aulas de sociologia para o então segundo grau, tendo acompanhado, no fim da década de 1980, as discussões relativas à Constituinte mineira, principalmente quanto ao retorno da 
obrigatoriedade do ensino de sociologia no segundo grau para as escolas públicas do estado. Poucos anos antes, ao ingressar como docente na Universidade Federal de Uberlândia, ela havia escrito um texto sobre o tema, em relação ao qual passou a atuar de forma mais ampla e direta principalmente por seu envolvimento quanto às discussões relativas à aprovação da Nova Lei de Diretrizes e Bases, em 1996.

Ileizi Fiorelli Silva também foi professora de segundo grau antes de ingressar como docente da Universidade Estadual de Londrina (UEL), em que fez a graduação. Desde esse período, participava de fóruns estaduais pelo retorno da sociologia ao Ensino Médio, juntamente ao centro acadêmico, e quando professora na educação básica, recebia os alunos de estágio em ciências sociais, inserindo-se em eventos sobre o tema a convite das professoras da licenciatura Lesi Correa e Marcolina Carvalho. Junto a elas, e às professoras Benilde Bischop e Maria José de Rezende, realizou o projeto de extensão "O retorno da sociologia ao segundo grau", percorrendo as escolas vinculadas à Diretoria de Ensino de Londrina para convencer seus gestores a incluir a sociologia na parte diversificada, e oferecendo assessoria àquelas que o fizeram, contribuindo para o reconhecimento da atuação da UEL junto às escolas de educação básica.

Então foi um período que eu acho que essas professoras, eu aprendi muito com a professora Lesi Correa. (...) Então isso nos ajudou muito, muito, na inserção aqui do Paraná, de Londrina em especial, né, do Paraná. E depois a inserção nacional foi se dando por essas experiências. As pessoas sabiam. "Nossa em Londrina, vocês tão fazendo isso de interessante, tem esse projeto. Vem aqui contar para nós". E a gente foi juntando com colegas dos outros estados. - Ileizi Silva.

Heloísa Martins não atuou como professora da educação básica, entretanto compôs, em 1998, a equipe do Ministério da Educação responsável pela elaboração das Diretrizes Curriculares Nacionais dos cursos de Ciências Sociais, tendo sido indicada pelo departamento de sociologia da Universidade de São Paulo (USP), no ano anterior, devido a seu interesse pela graduação em ciências sociais.

Devido a esta tarefa, após o término da redação das Diretrizes, ela começou a participar de encontros de cursos de ciências sociais pelo país, nos quais era questionada sobre a licenciatura, que era considerada um problema em muitos deles. Embora esta não fosse responsabilidade da equipe de que fazia parte, pois havia sido composto um grupo responsável especificamente pelas Diretrizes para as licenciaturas, Heloísa tomou contato com o projeto do Dep. Roque Zimmerman, e ficou a par da existência de um movimento, encabeçado pelo SINDSESP e pela FNSB, pela sua aprovação. 
Só que aí eu comecei a perceber que já havia um projeto do Padre Roque (Zimmerman) propondo a volta da sociologia e da filosofia no Ensino Médio. E eu comecei a ver que havia por parte dos sindicatos, da Federação dos Sociólogos (...) e em vários lugares do Brasil existia já essa articulação, essa movimentação para a criação do ensino de sociologia. - Heloísa Martins

Amaury Moraes, pouco após assumir o cargo de professor da Universidade de São Paulo, em 1999, foi convidado por uma colega do departamento de História para ir a um evento sobre ensino de sociologia, organizado pelo SINDSESP e pela FNSB em parceria com o departamento de sociologia da universidade. Durante a mesa-redonda, em que se discutia o projeto de lei do Dep. Roque Zimmerman, ele percebeu que os membros não estavam abordando a questão das Diretrizes Curriculares Nacionais do Ensino Médio, documento escrito no ano anterior por Guiomar Namo de Mello, conselheira do Conselho Nacional de Educação, e que indicava que as disciplinas de sociologia e filosofia deveriam estar no currículo de modo contextualizado interdisciplinarmente. Quando se manifestou a este respeito, as pessoas presentes, que ignoravam o conteúdo das Diretrizes, pediram que ele as esclarecesse a respeito, e que compusesse a mesa para tratar dessa questão, sendo solicitado a ele após sua fala que escrevesse um texto para a revista da APEOESP (MORAES, 1999). A partir deste fato, seu envolvimento com este processo foi se acentuando, e sua participação, bem como a de Heloísa Martins, começou a ser solicitada por Paulo Martins e Lejeune de Carvalho, então presidentes do SINDSESP e da FNSB, nos encontros de cursos de ciências sociais que as entidades sindicais estavam realizando pelo país.

O envolvimento de Sueli Mendonça se deu um pouco depois, quando, além dos sindicatos, a Sociedade Brasileira de Sociologia passou a se envolver mais diretamente com as movimentações em torno do retorno da obrigatoriedade. Professora da licenciatura e responsável pelo estágio supervisionado do curso de ciências sociais do campus de Marília da Universidade Estadual Paulista, ela já trabalhava com o tema, e em 2003, no Congresso Brasileiro de Sociologia, tomou parte neste movimento. Segundo ela, embora a SBS tivesse um papel fundamental em sua organização,

(...) era o Sindicato dos Sociólogos de São Paulo, o SINDSESP, que tinha, vamos dizer, essa liderança, e organizava encontros dos coordenadores de curso de ciências sociais pelo Brasil, então tinha reuniões, eu lembro, meio sistemáticas, periódicas, e na figura do Paulo Martins, que nem sei se ele ainda está à frente, faz tempo que eu não encontro com ele, e do Lejeune Mato Grosso. - Sueli Mendonça

Desse modo, embora houvesse indivíduos, grupos e instituições preocupados com o retorno da sociologia como disciplina escolar obrigatória, estes, até meados da 
década de 1990, não se encontravam organizados enquanto um movimento relativamente uno e coeso. Esta articulação, centrada em torno da aprovação do Projeto de Lei ${ }^{\circ}$ 3.178, apresentado pelo Dep. Roque Zimmerman, foi inicialmente instituída pela ação de sindicatos, sendo os principais a FNSB e o SINDSESP.

Ambos, gradativamente, foram agregando a participação de cientistas sociais que atuavam ou tinham afinidade com a questão do ensino de sociologia, inserindo-os em seus quadros de integrantes ou demandando sua participação em eventos.

(...) nos anos 90, um pouquinho antes da LDB, e depois da LDB, até mais ou menos 2002, assim, 2003, vamos colocar aí, os agentes principais eram o Sindicatos dos Sociólogos do Estado de São Paulo e a Federação Nacional dos Sociólogos. (...) Então o Lejeune Mato Grosso Xavier que era o presidente do sindicato e da Federação. Nessa época ele chamava e demandava muito o professor Amaury Moraes, que tinha entrado fazia pouco lá na Faculdade de Educação nessa disciplina, de Metodologia (de Ensino). O professor Nelson Tomazi, que tinha organizado um livro didático de iniciação à sociologia (...) Por conta disso, o Lejeune também demandava o professor, e o professor se inseriu na Federação, como secretário, como responsável pela questão do segundo grau, na época era segundo grau. Então esses personagens, esses agentes foram muito importantes nesse período. Um porque tinha o livro, mas não só por que tinha o livro, mas se inseriu na luta, né? O Amaury porque assumiu a disciplina de Metodologia e o Lejeune que era o que fazia as articulações. - Ileizi Silva

Criaram-se, assim, duas frentes principais de atuação. Uma junto às instituições de ensino de ciências sociais, por meio da realização de encontros de cursos de graduação, e outra junto a deputados e senadores participantes das negociações e votações em torno da aprovação ou não deste projeto no Congresso Nacional. No primeiro caso, embora tenha havido a participação e o engajamento de muitos cientistas, houve também resistência por parte de diversas pessoas e instituições, não se constituindo as instituições de ensino, em geral, como partícipes significativos para a tentativa de aprovação do referido projeto.

Porque as instituições formadoras, as universidades ou faculdades nunca tiveram um papel propositivo, de luta, de enfrentamento, de, como é, moção de apoio, preocupação, junto a nada. - Sueli Mendonça

$\mathrm{Na}$ verdade, se centrava assim: os professores lá das instituições superiores dos cursos não estão interessados na licenciatura. É verdade. Raríssimas exceções. Raríssimas. - Heloísa Martins

Nas federais e nas estaduais, o coordenador, você sabe, o professor é contratado por concurso. Ele é um servidor público estadual ou federal. Se o mercado de trabalho é amplo ou é pequeno, se tem sociologia no Ensino Médio ou não tem, não altera o salário dele, a quantidade de horas que ele dá, entendeu? Ele não tem nenhuma preocupação em disputar aulas porque ele já é concursado né? Então nós sentimos pouco engajamento. Isso é uma realidade que eu também menciono de forma secundária para não causar 
problemas políticos, né? Mas poucos foram os coordenadores que ajudaram muito. - Lejeune de Carvalho

Quanto à atuação junto aos atores políticos, esta foi realizada, principalmente, por Lejeune de Carvalho, que por diversas vezes foi a Brasília acompanhar as apreciações e votações do projeto de lei, e argumentar com cada um dos envolvidos para buscar que se posicionassem favoravelmente à aprovação.

Para financiar estas viagens, o SINDSESP e a FNSB contaram com o apoio, sobretudo, do Sindicato dos Professores do Ensino Oficial do Estado de São Paulo (APEOESP) e, posteriormente, da Sociedade Brasileira de Sociologia (SBS). Por isso, para Lejeune de Carvalho,

Sem a APEOESP essa lei não modificaria. Várias das minhas viagens até Brasília eles que ajudaram a financiar. Um encontro nacional que fizemos em 2007 no Anhembi com mil pessoas, eles que ajudaram a bancar. Ou seja, o grande agente como você diz, o grande autor, a grande instituição coletiva foi o sindicado dos professores do ensino oficial de São Paulo. - Lejeune de Carvalho.

O veto integral do presidente Fernando Henrique Cardoso (1995-2002) ao projeto, em 2001, constitui-se simultaneamente como desapontamento e estímulo à atuação do grupo, produzindo novas estratégias e formas de organização, centradas na obtenção desta obrigatoriedade nos estados, e na conquista de espaços institucionais acadêmicos, como as reuniões e congressos da Sociedade Brasileira de Sociologia, Sociedade Brasileira para o Progresso da Ciência (SBPC) e Associação Nacional de Pós-Graduação em Ciências Sociais (ANPOCS).

Nós orientamos ir para os estados e aprovar nas Assembleias Legislativas, ou aprovar nos Conselhos Estaduais de Educação, ou aprovar por decreto na Secretaria de Educação. (...) Quando nós aprovamos a Lei em maio de 2008 no Plenário e no Senado, o nosso balanço é que 17 estados, 16 e mais o Distrito Federal, já tinham a sociologia. Ou seja, nós fomos comendo pela borda. Essa foi a estratégia, a orientação que nós demos né? Claro que eu apresentei essa proposta, mas ela era aprovada pelos fóruns, né? Pelas comissões, pelos sindicatos dos estados. - Lejeune de Carvalho

(...) em outubro o presidente Fernando Henrique Cardoso veta o projeto, dizendo que, falta de verba, a sociologia e a filosofia já estavam contempladas, isso ia mudar a autonomia das escolas.... Várias razões, né? E aí o pessoal continuou me pedindo para eu escrever a respeito, participar, discutir. (...) Então em 2001 ainda eu participei de um evento em Fortaleza, da SBS. Então a Federação consegue um espaço dentro do congresso da SBS em Fortaleza, onde ela apresenta um debate sobre o ensino de sociologia, e aí eu participo também desse evento. - Amaury Moraes

(...) foi quando a gente resolveu então, e a própria Federação fez um encontro, uma participação num congresso da SBS em Fortaleza. A gente fez um fórum sobre isso. Fórum assim, o congresso está lá, o fórum era uma coisa meio externa. Como o Lejeune dizia na época: "O fórum é uma coisa de fora". (Risos) - Nelson Tomazi 
No início dos anos 2000, com a inserção de Heloísa Martins na SBS como diretora, representado o estado de São Paulo, foram-se granjeando espaços nos eventos promovidos por esta instituição para realizar discussões sobre o ensino de sociologia, embora, inicialmente, estes ocorressem sob a forma de fóruns, realizados de forma anexa aos congressos da SBS, que não incorporavam, de fato, a temática. Heloísa também conseguiu espaços de debate, como mesas-redondas e fóruns, em reuniões anuais da SBPC, e em encontros da ANPOCS, o que foi bastante significativo, posto contribuir para a aquisição de legitimidade acadêmica para o movimento, então taxado, muitas vezes, como corporativista.

Nós como professores das universidades fazíamos meio um jogo duplo, né? De tanto trabalhar junto com a Federação, com os sindicatos e a Federação, como também com as sociedades científicas, que na verdade era só a SBS. E daí a gente começa a fazer essa ponte também, de vez em quando juntava tudo, por exemplo, no congresso da SBS de Fortaleza, nós fomos para lá, participamos de atividades uns dois, três dias, né? Mas ainda era um pouco fora, né? Ainda na universidade de Campinas quando teve a SBS de 2003, ainda éramos fora, tanto que o que foi organizado foi um fórum, e aí os debates todos, tudo. - Amaury Moraes

E eu, nesse meio tempo, eu comecei a participar da Sociedade Brasileira de Sociologia. Primeiro eu fui como diretora representando aqui São Paulo. Depois eu fui primeira secretária, segunda secretária, não sei bem o que. E nesse envolvimento eu comecei a levar para dentro da SBS a proposta da discussão do ensino de sociologia. Fazendo no congresso da SBS, na ANPOCS, propondo fóruns, mesas redondas, sabe? Eu e outras pessoas que estavam aí envolvidas, para que essas discussões fossem feitas nesses solos, né? Para levar para a sociedade, para a SBS, para a ANPOCS, esse debate. Heloísa Martins

Então nós tivemos eventos em 2004 na ANPOCS, em outubro de 2004, em 2005, 2006, 2007, 2008, todos os anos, porque a professora Heloísa normalmente intervinha e aí ela conseguiu um espaço para a gente discutir também na ANPOCS. - Amaury Moraes

(...) a professora Heloísa Helena Martins foi muito importante, (...) muito importante porque ela abriu as portas da USP para nós. O professor Amaury é da USP, mas a professora Heloísa é como se ela abrisse as portas. "Olha, nós vamos ter esse congresso, vamos ter esse encontro, e nós vamos reservar essa parte aqui, esse pedaço, esse espaço, esse tempo para discutir o ensino de sociologia". No começo a gente discutia à noite. Então o ensino de sociologia vai ser discutido à noite: "Ah, beleza, nós vamos ter uma sala, vamos ter cadeiras, vamos ter um quadro". - Elisabeth Guimarães

(...) e aí a professora Heloísa Martins teve um papel fundamental para essa articulação, e outros foram se agregando, Amaury Cesar Moraes, enfim, muito atuante, no início desse processo, e aí a gente foi conseguindo desenvolver via essas mobilizações via a SBS, e também via os encontros organizados pelo Sindicato dos Sociólogos, né, porque enquanto a SBS não se mexia muito, o Sindicato tinha um, teve um papel muito importante pela volta da sociologia. - Sueli Mendonça 
Em função desta atuação, e de sua participação na elaboração das Diretrizes Curriculares, Heloísa Martins foi indicada pela SBS, em 2004, para fazer parte do Fórum Curricular Nacional do Ensino Médio, que estava sendo criado pelo Departamento de Políticas do Ensino Médio da Secretaria de Educação Profissional e Tecnológica (SETEC) do Ministério da Educação, reunindo estudiosos de diversas entidades científicas. Após comparecer a uma das reuniões, ela decidiu indicar que Amaury Moraes ocupasse seu lugar neste Fórum, e que ele passasse a ser recomendado pela SBS para a realização de tarefas semelhantes.

Porque quando eu comece a ir naquelas reuniões lá, as primeiras reuniões que
juntavam aquelas entidades todas, chegou um ponto, eu falei, eu não tenho o
que fazer aqui. Tem que estar aqui alguém que trabalhe com metodologia de
ensino. Virei para o Amaury e disse: "Olha, acho que de agora para a frente,
invés da SBS indicar o meu nome, vai indicar o seu para ir para Brasília
participar dessas reuniões". - Heloísa Martins
E a professora Heloísa Martins foi indicada então para participar desse
evento. Ela então foi numa reunião e percebeu que ali a discussão, ali era um
povo envolvido com educação, das entidades, mas envolvido com educação,
e ela era, vamos dizer assim, ela se considerava pouco envolvida, muito
interesse, mas não entendia da coisa suficientemente. Então como a gente
estava esses anos todos, eu e ela, desde 1999 andando pelo Brasil, coisa e tal,
participando de eventos, ela falou: "Então vamos indicar você". Me indicou,
e eu fui participar desse Fórum. - Amaury Moraes

Como membro deste Fórum, Amaury Moraes questionava, nas reuniões, as Diretrizes e os Parâmetros Curriculares Nacionais, ficando decido, a partir das discussões em torno desses temas, que seriam realizados debates nas diferentes regiões do país, com o intuito de, baseando-se neles, elaborar posteriormente um documento, cujo nome seria Orientações Curriculares do Ensino Médio. Amaury Moraes convidou, para participarem deste Fórum, Elisabeth Guimarães e Nelson Tomazi, e participaram ambos, assim como ele, de eventos em diferentes estados, realizando-se a síntese destas discussões em Brasília, no fim de 2004.

No ano seguinte mantiveram-se as reuniões do Fórum, e em uma delas, no início do ano, Amaury Moraes procurou o coordenador da equipe de filosofia, João Carlos Salles, e fez a ele uma proposta de negociação.

Eu fui falar com o professor de filosofia, com o representante de filosofia, e falei: "Olha, eu acho que o seguinte, eu não estou a fim de continuar nessa situação se sociologia não se tornar uma disciplina obrigatória, se o MEC (Ministério da Educação) não assumir nenhuma responsabilidade com isso". Daí ele falou: "Bom eu concordo, eu vou propor a mesma coisa com filosofia”. Então nós pedimos uma reunião com a professora Lúcia ${ }^{1}$, à parte,

\footnotetext{
${ }^{1}$ Lúcia Helena Lodi, coordenadora do Fórum.
} 
fomos lá e falamos: "Olha, a gente não continua, porque nós vamos aqui pintar papel de preto para não valer nada. Então se o MEC assumir um compromisso de levar uma mudança nas Diretrizes para a gente tornar obrigatórias as disciplinas, a gente continua na equipe, senão a gente vai embora e vocês chamam outras pessoas". Meio que abusados nós dois fomos. Daí ela falou: "Tudo bem, vou levar para a equipe, se a equipe tiver uma posição a favor a gente manda ver". Porque a gente tinha discutido muita coisa, tinha meio feito diferença naquele debate, e a equipe toda eram as treze disciplinas, pensa bem, concordou, apoiou. - Amaury Moraes

A partir dessa decisão definiu-se que seria elaborado um Parecer sobre as Diretrizes Curriculares Nacionais, e que este seria encaminhado ao Conselho Nacional de Educação, para que este fizesse as alterações necessárias para que sociologia e filosofia passassem a ser tratadas como disciplinas, ficando Amaury Moraes e João Carlos Salles responsáveis pela redação do documento. Paralelamente a isso, Amaury Moraes, Elisabeth Guimarães e Nelson Tomazi, começaram a elaborar as Orientações Curriculares de Sociologia.

Quando o Parecer sobre o ensino de Filosofia e de Sociologia ficou pronto, as diversas entidades envolvidas com o retorno da sociologia como disciplina escolar (SINDSESP, FNSB, SBS, APEOESP, entre outras) participaram de uma reunião convocada por Lúcia Lodi para discuti-lo, e todas o apoiaram, apesar de algumas discordâncias.

No fim, na verdade o Parecer saiu como eu tinha elaborado. Havia um aqui e ali, porque a Federação não concorda com o termo cientista social, né? E eu escrevo cientista social no Parecer, que repugna a um cientista social acreditar que as coisas sejam naturais, coisa e tal, e eles achavam que tinha que colocar sociólogo. E foi uma briga, aquela coisa toda. Como eu pensava na coisa de que o licenciado em sociologia deveria também ser sociólogo, então eu pensava muito mais em termos de cientista social do que de sociólogo stricto sensu. Além do que eu sempre pensei que deveríamos trazer o cientista político e os antropólogos para a nossa causa. Porque sociologia nunca foi sociologia, só. O que sempre foi ensinado foram as três ciências sociais, e às vezes até economia e direito, né? Então eu nunca achei essa coisa, essa divisão de só sociólogo, né? - Amaury Moraes

Ainda em 2005 foram criados, no $12^{\circ}$ Congresso Brasileiro de Sociologia, o Grupo de Trabalho "Experiências de Ensino de Sociologia; Metodologias e Materiais Didáticos", cuja coordenação ficou sob responsabilidade de Amaury Moraes, e a "Comissão de Ensino" da Sociedade Brasileira de Sociologia, coordenada por Heloísa Martins.

Como eu estava na SBS, eu me lembro que houve uma reunião no MEC com as associações dessas entidades representativas dessas diferentes disciplinas. E eu fui pela SBS. E lá eu fiquei espantada, que várias das associações, especialmente a de matemática, eles tinham comissões de ensino, sabe? Aí eu falei: "Pô, a gente podia criar uma Comissão de Ensino". Voltei para São 
Paulo. Reuni com os colegas, e eu me lembro que houve no congresso de Minas Gerais, o congresso da SBS em Minas Gerais, eu não me lembro se foi 2005, não sei, por aí. Eu conversei com os colegas que a gente podia propor uma comissão de ensino. Eu estava na mesa, eu era uma das secretárias lá e eu estava na mesa que ia discutir a questão da, ia discutir várias coisas. Então eu propus para o Nelson Tomazi - ele vai dizer que ele é que propôs - que na assembleia, como eu estava na mesa diretora, eu não ia fazer a proposta. Então eu disse: "Alguém tem que fazer", e ele disse: "Eu faço". "Então faça uma proposta de uma comissão de ensino". E foi feita, ele fez a proposta. Levada para a mesa, a mesa levou para a diretoria, e eu defendi a proposta na diretoria. (...) E foi criada a comissão. A Comissão de Ensino era uma comissão da SBS que indicava o seu coordenador. (...) A diretora da SBS disse: "Então, já que você discute aqui a questão da sociologia no Ensino Médio, você vai ser a coordenadora da comissão". Eu disse: "Tudo bem". Aí criamos a comissão e eu comecei como coordenadora da comissão. - Heloísa Martins

Neste congresso tivemos a primeira presença definitiva com duas Mesas e o primeiro GT. E foi neste Congresso que se criou a Comissão de Ensino. Mas aqui são necessários alguns detalhes. Quem se levantou na assembleia para propor a criação de um Comitê de Ensino de Sociologia fui eu, pois a maioria da assembleia conhecia minhas posições. A Prof ${ }^{a}$ Heloisa propôs o nome de Comissão de Ensino e foi indicada pelo Presidente Tom Dwyer para coordená-la. - Nelson Tomazi (Carta aberta para outros esclarecimentos e para incrementar o debate, enviada à Comissão de Ensino da SBS em 2011²)

Após a aprovação, pelas entidades, do Parecer sobre o ensino de Filosofia e de Sociologia, o Ministério da Educação decidiu apoiá-lo, e mandar a proposta para o Conselho Nacional de Educação (CNE), então presidido por Cesar Callegari, que novamente convidou as entidades envolvidas para uma reunião. Participaram desta pareceristas do $\mathrm{CNE}$ que haviam recebido o documento e estavam resistentes à sua aprovação, devido à lista de disciplinas que, assim como sociologia e filosofia, buscavam entrar no currículo obrigatório.

Após esta reunião, Cesar Callegari e Amaury Moraes se encontraram em um evento organizado pela APEOESP, e tiveram uma discussão em torno da aprovação do Parecer. Alguns dias depois, o primeiro pediu uma reunião, indo até a Faculdade de Educação da USP para realiza-la.

Acabamos conversando, e ele falou: "Olha, é muito difícil aprovar desse jeito", e eu falei: "Bom, nós temos alternativa. É: a sociologia e a filosofia se tornam obrigatórias como disciplinas nas escolas em que todas as disciplinas são disciplinas. Nas escolas em que não há disciplinas, então ela pode ser interdisciplinar como todas as outras". E é isso que saiu do Parecer, né? Do Parecer dele (CEN/CEB n 38/06), que acolhe o meu Parecer, mas que dá essa visão, porque segundo ele haveria muita dificuldade em dizer que sociologia e filosofia iam se tornar obrigatórias. Então eu falei: "Então a alternativa é essa". Porque eu falava para ele: "Olha, se você me apresentar uma escola em que não há disciplinarização, que as disciplinas não são obrigatórias, eu abro mão de qualquer coisa, aí não discuto mais". Não tem, não existe isso. Em toda as escolas, em todo Ensino Médio, tudo é disciplina,

\footnotetext{
${ }^{2}$ Disponibilizada para esta pesquisa pelo autor.
} 
né? Mesmo arte, mesmo educação física, são disciplinas. Então ele colocou essa, vamos dizer assim, armadilha. Não quer que seja disciplina? Então tem que dizer que o currículo é aberto. Se são disciplinas todas as outras, sociologia e filosofia também serão disciplinas. É isso que está lá no Parecer. - Amaury Moraes

O Parecer sobre o ensino de Filosofia e de Sociologia foi aprovado, então, pelo Conselho Nacional de Educação, em 2006, mesmo ano em que foram publicadas as Orientações Curriculares Nacionais.

(...) quando o Fernando Henrique veta a determinação lá, a saída volta a ser o Congresso Nacional. Mas aí o Congresso Nacional para votar e derrubar o veto, tudo mais, é um processo muito difícil. Então o que acontece, quando eu escrevo o Parecer e o Parecer é aprovado pelo Conselho Nacional de Educação, isso ganha uma importância institucional. Não é o Sindicato, não é a Federação, não é simplesmente um, como eles costumam dizer, um corporativismo. Está um debate aí também educacional mesmo. Educacional mesmo. - Amaury Moraes

No início o Amaury teve um papel fundamental, ele era a principal pessoa mesmo, tanto que foi ele que fez o Parecer, a gente não pode esquecer, ele é uma pessoa estratégica ali. E nessa andança pelo Brasil via o sindicato a gente foi conseguindo juntar as forças e de alguma forma ter alguma mobilização em alguns estados que foi importante depois para a luta nacional. - Sueli Mendonça

Nessa mesma época, Heloísa Martins se tornou $1^{\mathrm{a}}$ secretária (2006-2007) da Sociedade Brasileira de Sociologia, então presidida por Tom Dwyer (2006-2009), que apoiou o movimento pela obrigatoriedade da sociologia como disciplina escolar, de modo que, nesse período, já havia se constituído uma rede de relações pessoais e institucionais relativamente organizada, cuja atuação se dava tanto no âmbito sindical e político, quanto no acadêmico e educacional.

Então o Tom ia a Brasília junto com o Lejeune. A Heloísa ia nos debates do MEC e depois passou a indicar o professor Amaury Moraes para ir, quando ela achava que ele entendia mais. Por sua vez, o professor Amaury demandava outras pessoas. O próprio Nelson Tomazi, a Elizabeth Guimarães da Federal de Uberlândia, por todo protagonismo em relação ao vestibular, que é desde 1997 que tem sociologia né? E às vezes eu também. - Ileizi Silva E junto com tudo isso houve todo um trabalho de pesquisa. A gente não lutou por lutar, a gente lutou pesquisando sobre o histórico da sociologia, pesquisando quais as escolas que tinham sociologia, quais os estados que não tinham, quais os estados que nós poderíamos contar com eles, sabe? (...) Então não foi uma luta unicamente política. Foi uma luta acadêmica, foi uma luta de pesquisadores. Isso aí tem que ficar claro, porque não foi uma luta de palanque, foi uma coisa assim que foi feita por pessoas que eram acadêmicas, que se debruçavam sobre conhecimento, livros antigos e, assim, tentando, cada vez, colocar uma linha, duas linhas a mais: "Olha, descobri isso, descobri aquilo", mas tudo em cima de uma proposta de conhecimento acadêmico científico, tá? (...) E isso aí vai acontecendo o seguinte, é que algumas pessoas entram no movimento, outras saem, mas tem um grupo que continua, e esse grupo que continua é justamente o grupo que tem aquele propósito de fazer com que a sociologia volte. Não é que os que entram e saem fossem contra ou a favor, mas eles não teriam essa perseverança para 
lutar por esse tipo de situação, né? E no meu caso, eu tive a sorte de encontrar com pessoas que pensavam da mesma forma, que me fizeram convites, e que eu pude fazer convite para elas. (...) Eu sempre tive a convicção, mas essas pessoas, essas situações, elas foram me proporcionando a capacidade de me incluir no movimento de uma forma assim, vamos dizer, mais efetiva. Elisabeth Guimarães

Durante o transcorrer deste processo, o estado de São Paulo se manteve bastante resistente à implantação da sociologia como disciplina obrigatória, rechaçando a medida tomada pelo Conselho Nacional de Educação, e questionando sua autoridade para legislar sobre disciplinas, alegando que esta ação feria a autonomia dos sistemas de ensino. Em função da proximidade entre a então secretária da educação de São Paulo, Maria Helena Guimarães, e Tom Dwyer, Heloísa Martins, que na época tinha se tornado vice-presidente da SBS a convite dele, sugeriu que marcasse uma audiência com a secretária, para tentar obter seu apoio ao Parecer feito por Cesar Callegari. Além disso, requisitou o apoio de José de Souza Martins, seu marido, devido ao prestígio e reconhecimento detido por este.

O problema é que ninguém mais da universidade se manifestava sobre essa questão. E aí entra relações familiares. Eu achava que alguém da universidade, alguém de peso, que tivesse, sei lá, um nome respeitável, se pronunciasse sobre a questão da sociologia no ensino médio. E eu pedi para o meu marido escrever um artigo no Estadão. Eu falei "Olha, não é possível. Você não é a favor da sociologia no Ensino Médio?" E ele era. Falei: "E não fala nada?". Ele falou: "É, mas eu não escrevo, eles me, há uma pauta, precisa entrar na pauta". E eu falei: "Sugira, sugira". E ele escreveu um artigo (Martins, 2008). E foi fundamental. (...) Esse artigo, eu tenho certeza, foi dito explicitamente, que quando o Tom (Dwyer) foi pedir a audiência com a secretária ela disse: "Tudo bem, recebo vocês, mas quero que o professor José de Souza Martins venha também na reunião". Aí foi marcada a reunião. - Heloísa Martins

Nesta, Maria Helena Guimarães se comprometeu com o retorno da sociologia e da filosofia para o currículo obrigatório no ano seguinte, mas ressaltou que, para este regresso, era necessário que houvesse uma proposta curricular para sociologia, assim como para filosofia, e que estava sendo realizada uma reformulação das propostas curriculares de todas as disciplinas do ensino básico, bem como a elaboração de cadernos (apostilas didáticas) para professores e alunos.

E ela chega e diz: "Bom, vai ter que refazer a proposta curricular. A SBS está interessada em fazer essa proposta?" A hora que ela formulou isso, imediatamente uma assessora dela disse: "Porque se vocês não quiserem, tem quem faça”. Não era interesse da SBS fazer essa proposta curricular, não era nada. Nós estávamos envolvidos na questão da volta da sociologia, achando que isso depois os professores, a secretaria, isso fosse feito. Nós não queríamos. A SBS sempre foi uma instituição muito marcada pela pósgraduação. (...) Então não era a nossa ideia, mas na hora que ela disse isso imediatamente o pessoal ali, estava o Amaury, estava o Tom, estava o meu 
marido, não sei mais quem, ela quis que ele fosse porque tinha lido o tal artigo. E aí imediatamente a gente: "Não, a gente faz, a gente faz". - Heloísa Martins

Diante do comprometimento da SBS em fazer este trabalho, Heloísa foi designada, como coordenadora da Comissão de Ensino, para montar um grupo com professores do estado de São Paulo, e coordená-lo, do qual fazia parte Amaury Moraes.

Além desses acontecimentos, a eleição do presidente Luís Inácio Lula da Silva (2003-2010), bem como a alteração dos ministérios e da composição do Congresso Nacional, especialmente em seu segundo mandato, foi de extrema importância para o retorno do ensino de sociologia ao Ensino Médio, por meio da aprovação do PL 1.641/03, do deputado Ribamar Alves.

Bom, e aí o governo, o MEC, resolveu abraçar a luta. As coisas ficaram mais fáceis. Eu tive sete audiências com o Ministro Fernando Haddad em Brasília e com seu secretário executivo, o professor Francisco das Chagas, que é professor de Pernambuco. O Conselho Nacional de Educação, em abril de 2006, ele foi recomposto, porque o Lula herdou ainda conselheiros comandados do governo anterior, e não passava nada ali. A Bebel, inclusive, presidente da APEOESP, passou a ser conselheira nacional. O clima mudou no Brasil. E aí em 2008 foi muito fácil aprovar o projeto. Na Câmara passou por unanimidade e no Senado por unanimidade. Impressionante. Ninguém votou contra. Líderes que no governo anterior eram contra, votaram a favor. Isso porque o governo agarrou. Se dependesse só também da nossa pressão provavelmente não aprovaria. Então devemos muito ao governo do Presidente Lula. - Lejeune de Carvalho

Dessa maneira, quando foi feita a entrega da proposta curricular à Secretaria de Educação de São Paulo (SEESP), já havia se garantido o retorno da sociologia como disciplina obrigatória ao Ensino Médio, pela sanção da lei 11.684 pelo presidente em exercício José Alencar. Em nova reunião nesta Secretaria de Educação, Heloísa Martins e Amaury Moraes foram informados por Maria Inês Fini, coordenadora do Projeto São Paulo Faz Escola, e Paulo Miceli, coordenador das Propostas Curriculares de História e Filosofia, de que havia outra proposta além daquela da SBS, elaborada por este, e de que era o desejo da secretaria que ambas fossem combinadas.

Aí para resumir a história ela disse: "Olha, eu acho que vocês têm que juntar as duas propostas". Aí eu, que tinha folheado, falei: "Olha Maria Inês, são "injuntáveis"”. Nós temos uma concepção de currículo que eu não sei, pelo que posso apreender aqui, não tem nada a ver com que o Paulo colocou aqui. Nós estamos numa base bastante fenomenológica, eu acho que ele, eu não entendi ainda, preciso ler devagar, mas eu acho que não tem, é uma questão meio, eu acho que não vai dar para juntar". "Não, não, vocês vão lá, fazem, não sei o que". Eu falei: "Não, eu não vou fazer". Eu falei para o Amaury: "Eu não sei". Façam vocês e vamos ver o quê que a gente acha. (...) E quando eu li, aí eu falei para o Amaury e para o Tom: "Eu retiro a proposta, a nossa. Não tem nada a ver". Eu falei: "Olha, eu, se juntar a proposta, ele vai ser o coordenador, e eu não quero estar metida nesse rolo aí, nesse nível”. (...) Aí 
fomos para a tal reunião que ela chamou depois da gente ter lido o tal trabalho, com a decisão de que nós iríamos retirar a nossa proposta. - Heloísa Martins

Nesta reunião, Maria Inês Fini informou que a proposta curricular da SBS seria aceita, desde que Heloísa Martins assumisse a coordenação, tanto de seu desenvolvimento quanto da elaboração dos cadernos. Esta aceitou a tarefa mediante a condição de escolher quem comporia esta equipe, que foi integrada por duas ex-alunas da USP, Melissa de Mattos Pimenta e Stella Schrijnemaekers, que haviam enviado propostas quanto aos cadernos de sociologia. A proposta e o material foram implantados na rede estadual em 2009.

\section{Hierarquia, legitimidade e autoridade}

Grande parte dos agentes envolvidos no processo de disputas abordado acima, bem como da literatura científica sobre o tema, refere-se a ele como "luta pelo retorno do ensino de sociologia". Embora sua realização tenha envolvido diversas esferas de atuação, o objetivo final das ações, e motor primeiro da associação dos agentes, consistiu na aprovação da mudança do artigo 36 da Lei de Diretrizes e Bases da Educação Nacional, com vistas a que este explicitasse a obrigatoriedade da filosofia e da sociologia como disciplinas escolares.

Isto porque, devido ao histórico de intermitência das disciplinas no currículo obrigatório nacional, a sanção de uma lei que instaurasse a exigência desse ensino foi considerada a principal forma de garanti-lo. A existência de uma lei que explicita tão claramente essa necessidade evidencia a fragilidade de que estas dispunham enquanto matérias cuja presença no sistema de ensino fosse reconhecida e valorizada no país, pois a presença das demais disciplinas já se encontra naturalizada no currículo, não sendo seu ensino amplamente questionado ou avaliado como indesejável, e tampouco, sendo concebido como arbitrário, ou seja, como fruto de um processo histórico (BOURDIEU, 1998a).

Por conseguinte, a importância da ação junto ao Estado, principalmente ao poder Legislativo e Executivo, se dá em função da concentração e do exercício de poder simbólico por este que, para Bourdieu (2005), funciona como uma espécie de depositário de capital simbólico, possuindo autoridade para que atos arbitrários, como a instauração de uma lei, sejam atos de imposição legítima, portanto, amplamente 
reconhecidos, o que não ocorre na mesma medida quando são realizados por outras instâncias, como o exemplifica a resistência do estado de São Paulo em relação ao Parecer lançado pelo CNE em favor do ensino de sociologia e filosofia.

A sanção da lei 11.684 constituiu-se como a validação do ensino de uma série de representações do mundo social, vinculadas a áreas específicas do saber e da produção científica, cuja inculcação através do sistema escolar passa a ser imperativa em todas as instituições de Ensino Médio. Instaura, dessa forma, múltiplas mudanças envolvendo a educação básica e o ensino superior, consistindo em uma manifestação do poder simbólico detido pelo então ocupante do cargo presidencial, e exprimindo, por meio de sua aprovação, a legitimidade das instituições por este representadas (BOURDIEU, 1998a).

Para a obtenção desta legalização foi essencial o investimento dos agentes responsáveis em diversos âmbitos, envolvendo o trabalho nas esferas sindical, política, acadêmica, e junto à opinião pública, mobilizando diferentes formas de capital, sendo que o valor de cada uma destas depende da existência de um campo em que a competência que representam seja considerada eficaz, e valorizada tanto como instrumento quanto como objeto das disputas, permitindo a seus possuidores “existirem” neste espaço social.

Como sociedades como a nossa são configuradas por diferentes microcosmos sociais relativamente autônomos, ou seja, espaços sociais de relações objetivas que possuem uma lógica e uma necessidade específicas e não transponíveis a outros espaços, não há, nesta, um princípio de dominação absoluto, mas a coexistência concorrencial de formas diferentes de hierarquização relativamente independentes, sendo os diferentes poderes simultaneamente concorrentes e complementares (BOURDIEU; WACQUANT, 2008).

A amplitude da luta pelo retorno do ensino de sociologia foi perpassada pelas diferentes formas de hierarquia existentes nesses espaços sociais, bem como pela hierarquização que há entre eles, ocupando o Estado a posição dominante em relação aos demais, e sendo o campo acadêmico simultaneamente unido a ele e ao campo científico e intelectual (BOURDIEU, 2011).

Tais disputas adquirem simultaneamente o caráter de uma luta "interna" relativamente ao espaço social acadêmico das ciências sociais, perpassada pela conquista do apoio das instituições e da comunidade acadêmica, e de uma luta "externa" 
relativa à aprovação dos Projetos de Lei dos deputados Roque Zimmerman e Ribamar Alves, da aprovação da obrigatoriedade do ensino pelos estados, e da obtenção de apoio do CNE e do MEC. Embora operando em espaços sociais distintos, pautados por regras e normas de conduta específicas, e cuja autoridade tem como princípio diferentes formas de capital, em ambas o objetivo era a conquista de legitimidade para a sociologia como disciplina escolar.

Ao longo desse processo, o grupo de agentes responsáveis por organizar e realizar esta mobilização gradativamente foi constituindo-se e reconhecendo-se enquanto tal, conquistando sua oficialização principalmente por meio da criação da Comissão de Ensino da SBS, operando esta como uma espécie de transição do estado de grupo prático ao de grupo instituído, o que demanda a construção de um princípio classificatório que produza a reunião das propriedades distintivas que caracterizem o conjunto de seus membros, e que anule o conjunto das propriedades não pertinentes possuídas por eles, e que poderia servir como princípio formador de outras coletividades (BOURDIEU, 1998a).

Dentre as características comuns aos membros deste grupo, está a negação da procura por reconhecimento pessoal, tanto intelectual quanto monetário, bem como do interesse corporativo em conquistar a aprovação da obrigatoriedade, sendo característico da atividade intelectual que o investimento em relação a ela, perpassado pela ilusio do campo em que é realizado, contribua para que esta seja vivida como livre e desinteressada, em relação à definição comumente atribuída ao interesse, vinculada ao ganho material (BOURDIEU, 2001a). O funcionamento de todo campo, porém, produz e prevê uma forma específica de interesse, manifestando-se como o reconhecimento subentendido do valor dos objetos em jogo e do domínio prático das regras que devem ser seguidas para conquista-los (BOURDIEU; WACQUANT, 2008), de modo que a retribuição no campo acadêmico não é monetária, constituindo-se como o reconhecimento da autoridade científica, que nesse campo é uma propriedade legitimada e valorizada (BOURDIEU, 2005), sendo a virtude científica uma disposição socialmente constituída (BOURDIEU, 2001).

A posse desse tipo de capital contribuiu significativamente para a conquista de espaços institucionais em que este é o bem simbólico em disputa, sendo esta a razão pela qual Heloísa Martins, que dentre os agentes é quem possuía maior reconhecimento neste sentido, conseguia "abrir portas" em instituições de prestígio, para a discussão e 
produção sobre o ensino de sociologia. $\mathrm{O}$ acesso ao campo acadêmico, particularmente a seus espaços institucionais dominantes, exige que o agente detenha certas propriedades, sendo seu poder proporcional ao reconhecimento que recebe do grupo (BOURDIEU, 1998a), e crescente conforme a ocupação de posições que conferem “peso social” (BOURDIEU, 2011).

A relevância do envolvimento da SBS, assim como de espaços na ANPOCS e SBPC, para combater as acusações de corporativismo, significativamente presentes quando o movimento era liderado apenas pelos sindicatos, e comumente exteriorizadas por outros cientistas sociais, exemplifica a oposição e hierarquização, correntemente realizadas no espaço social acadêmico das ciências sociais, entre o universo das profissões e o universo da intelligentsia. Apresentam uma visão dicotômica do mundo do trabalho profissional, que desvaloriza a atuação de cientistas sociais fora de universidades e institutos de pesquisa, e que não confere prioridade ou relevância para as disputas profissionais relativas ao mercado de trabalho, fazendo o mesmo com as estruturas de representação desses interesses (BONELLI, 1993). Da mesma forma, quando se trata da luta "externa" travada pelos agentes, a representação científica geralmente é reconhecida como verdadeira, possuindo uma força social própria, e conferindo a seu detentor o monopólio do ponto de vista legítimo, que longe de ser visto como fruto de interesses pessoais, profissionais ou de classe, é identificado como neutro e desinteressado (BOURDIEU, 2011), desfrutando de uma autoridade superior à representação sindical.

O recurso a espaços institucionais identificados com o prestígio acadêmico, e principalmente à SBS, a partir da qual os agentes tiveram acesso a outras esferas dominantes, como o CNE e a SEESP, constitui-se como estratégico, sendo uma linha de ação objetivamente orientada, construída pelos agentes por meio de sua prática, e que possui no habitus, princípio não eletivo de todas as "eleições", a sua origem e a causa de sua adequação. Em função da coincidência produzida por este entre as disposições dos agentes, engendradas em grande parte por sua atuação neste espaço social, e as posições que eles ocupam no mesmo, o habitus contribui para que "façam o que têm que fazer", mesmo que nem todas as ações efetuadas sejam planejadas como metas (BOURDIEU; WACQUANT, 2008).

\section{Considerações Finais}


Ao longo da luta pela institucionalização do ensino de sociologia no Ensino Médio os cientistas sociais que a conduziram constituíram-se gradativamente como grupo organizado e relativamente coeso, atuando em diversas frentes de trabalho e mobilizando capitais diversos nas disputas em torno da aquisição de legitimidade da sociologia como disciplina escolar.

As decisões e ações estratégicas que empreenderam, aliadas a uma série de outros fatores estranhos a seu controle, como a mudança da composição do CNE, do MEC e do Congresso Nacional, contribuíram para o sucesso deste empreendimento, bem como para a aquisição de reconhecimento por estes cientistas em espaços institucionais basilares ao espaço social acadêmico das ciências sociais, como a SBS.

Embora certamente guiadas por seu conhecimento e experiência prévia nos diferentes espaços sociais em que atuaram, e engendradas em grande medida pelos habitus vinculados ao espaço social acadêmico das ciências sociais, estas ações, bem como os ganhos simbólicos delas decorrentes, não devem ser transformados, após o término deste processo, em intenções subjetivas ou em estratégias conscientes e calculadas, deliberadamente realizadas com o intuito de obter os lucros e consequências que delas resultaram.

Isto seria transformar “(...) o juízo da história, quer dizer, do historiador, em juízo final" (BOURDIEU, 2001a, p. 81), isto é, transformar o fim da história, apenas apreendido pela análise ulterior dos acontecimentos, em fim da ação histórica dos sujeitos que os vivenciaram.

\section{Referências}

BONELLI, M. da G. Identidade Profissional e Mercado de Trabalho dos Cientistas Sociais: as ciências sociais no sistema das profissões. 1993. Tese (Doutorado em Ciências Sociais) - Instituto de Filosofia e Ciências Humanas, Universidade Estadual de Campinas, Campinas, 1993.

BOURDIEU, P. A Economia das Trocas Linguísticas. Tradução de Sérgio Miceli. $2^{\mathrm{a}}$ ed. São Paulo: EDUSP, 1998a.

. Homo academicus. Tradução de Ione R. Valle e Nilton Valle. Florianópolis: Ed. da UFSC, 2011. Para uma sociologia da ciência. Tradução de Pedro Elói Duarte. Lisboa: Edições 70, 2001. 
O poder simbólico. Tradução de Fernando Thomaz. $4^{\text {a }}$ ed. Rio de Janeiro: Ed Bertrand Brasil, 2001a.

Razões Práticas. Tradução de Mariza Corrêa. Campinas: Paris, 2005.

BOURDIEU, P.; WACQUANT, L. Una invitación a la sociologia reflexiva. $2^{\mathrm{a}} \mathrm{ed}$. Buenos Aires: Siglo XXI Editores, 2008.

BRASIL. Orientações curriculares para o ensino médio: ciências humanas e suas tecnologias. v. 3, Brasília: Ministério da Educação, Secretaria de Educação Básica, 2006.

Parâmetros curriculares nacionais: ensino médio. Brasília: Secretaria de Educação Básica, 2000.

MARTINS, J. S. A Sociologia não volta às aulas. O Estado de S. Paulo [Caderno Aliás, A Semana Revista], São Paulo, p. J7, 10 de fev. de 2008.

BRASIL, Lei N 9.394 de 20 de dezembro de 1996, que estabelece as diretrizes e bases da educação nacional. Diário Oficial da União. Seção 1 - 23/12/1996, p. 27833, Brasília-DF, 1996.

BRASIL, Lei 11.684 de 2 de junho de 2008, que altera o art. 36 da Lei nº 9.394, de 20 de dezembro de 1996, que estabelece as diretrizes e bases da educação nacional, para incluir a Filosofia e a Sociologia como disciplinas obrigatórias nos currículos do ensino médio. Diário Oficial da União - Seção 1 - 3/6/2008, p.1 (Publicação Original), Brasília-DF, 2008.

MORAES, A. C.; Parecer sobre o ensino de Filosofia e Sociologia. Revista Mediações, v. 12, n. 1, p. 239-248, 2007. Disponível em <http://www.uel.br/revistas/uel/index.php/mediacoes/article/view/3404/2768> Acesso em 14 de maio de 2014.

Por que sociologia e filosofia no ensino médio? Revista Educação Apeoesp, São Paulo/Apeoesp, v. maio, n.10, 1999, p. 50-53.

TOMAZI, N. (Org.). Iniciação à Sociologia. 2aed. São Paulo: Atual Editora, 2000. 